\title{
Case Analysis of the Monitoring Data for a Roller Compacted Concrete Dam at Impoundment
}

\author{
Yang Shuai-dong*, Huang Zhi-huai \\ Hydraulic Engineering Research \& Technology Institute, The Pearl River Hydraulic Research Institute, Guangzhou, China
}

\section{Email address:}

ysdhhu@126.com (Yang Shuai-dong),412027498@qq.com (Huang Zhi-huai)

${ }^{*}$ Corresponding author

\section{To cite this article:}

Yang Shuai-dong, Huang Zhi-huai. Case Analysis of the Monitoring Data for a Roller Compacted Concrete Dam at Impoundment. Science Discovery. Vol. 4, No. 3, 2016, pp. 197-201. doi: 10.11648/j.sd.20160403.17

Received: June 30, 2016; Accepted: July 13, 2016; Published: July 20, 2016

Abstract: Based on the Nabi hydropower plant, the layout of the safety monitoring device for the roller compacted concrete (RCC) dam is introduced. The variations of some monitoring index during impoundment are analyzed and their evolution rules according to the variation of the water level are presented. The conclusions are made as follows: the osmotic pressure of the dam foundation and the uplift pressure of the upstream curtain are related to the water level; the stability of the dam can be affected by the heat of hydration due to concrete pouring; the water cooling system can effetely inhibit the crack; The impoundment has little effect on the bolt stress meter equipped at the bottom plate of the stilling basin and the reinforcement bar meter located on the surface; there is a negative correlation between their stress state and the temperature.

Keywords: Roller Compacted Concrete Dam, Monitor, Impoundment, Data Analysis

\section{碾压混凝土坝下闸蓄水期间监测资料实例分析}

\section{杨帅东 ${ }^{*}$, 黄志怀}

水利工程技术研究所, 珠江水利委员会珠江水利科学研究院, 广州, 中国

邮箱

ysdhhu@126. com（杨帅东），412027498@qq.com（黄志怀）

摘要: 本文结合那比水电站工程, 介绍了该电站碾压混凝土坝安全监测设施布置情况, 并对下闸蓄水期间各监测指标 的变化情况进行分析, 阐述了大坝各监测指标随水位变化的变化规律。研究结果表明: 坝基渗透压力和帷幕下游扬压 力水位与坝前水位相关; 坝体稳定受混凝土浇筑水化热影响较大, 通水冷却可有效控制温度裂缝的产生; 消力池面板 针杆应力计及钢筋计受下闸蓄水影响不大, 其受力与混凝土温度成负相关性。

关键词：碾压混凝土坝，监测，下闸蓄水，资料分析

\section{1. 引言}

中国是坝工大国, 截至 2007 年, 已建成各类水坝 8.7 万余座, 在经济建设和社会发展中发挥重要作用 $[1]$ 。大
坝安全监测设计与施工技术是大坝安全监测技术的重要 环节, 历来为监测界所重视 [2]。

对水利工程而言, 下闸蓄水期是对工程的重大考验 [3]。因此, 对大坝蓄水期的监测资料进行分析, 可以 掌握大坝的实际工作性态, 为大坝的安全运行提供必要 
的信息 [4]。为了实现上述目的, 监测资料分析时应结 合工程结构特点、施工方式、运行环境等情况, 以坝工 理论为基础, 综合分析大坝的安全性态, 及时反馈分析 结果 $[5]$ 。

\section{2. 工程概况}

\section{1. 大坝概况}

那比水电站坝址位于广西壮族自治区田林县境内驮娘 江与西洋江汇合口上游 $16.3 \mathrm{~km}$ 处的西洋江上。坝址控制集 雨面积 $4777 \mathrm{~km}^{2}$, 占西洋江流域面积 $5070 \mathrm{~km}^{2}$ 的 $94.2 \%$, 占右 江流域面积 $40204 \mathrm{~km}^{2}$ 的 $11.9 \%$, 多年平均流量 $59.9 \mathrm{~m}^{3} / \mathrm{s}$ 。水 库正常蓄水位 $355 \mathrm{~m}$, 总库容 5720 万 $\mathrm{m}^{3}$, 为日调节水库, 装 机容量48MW, 多年平均发电量 1.785 亿 $\mathrm{kWh}$ 。枢纽主要建筑 物有挡水坝、溢流坝及消力池、发电引水系统及水电站厂 房。大坝为碾压混凝土重力式挡水坝, 最大坝高 $68.5 \mathrm{~m}$, 坝 顶高程 $358.50 \mathrm{~m}$, 坝顶全长 $246.5 \mathrm{~m}$ 。坝体分为三段, 左右岸 为非溢流坝段, 长度分别为 $80 \mathrm{~m} 、 113.5 \mathrm{~m}$ 。溢流坝段布置在 河床中部, 长 $53.0 \mathrm{~m}$, 溢流净宽 $39.0 \mathrm{~m}$, 堰顶高程 $342.5 \mathrm{~m}$, 设 3 个有弧形闸门控制的孔口, 每孔宽 $13 \mathrm{~m}$, 高 $12.5 \mathrm{~m}$ 。溢流 堰采用WES曲线型实用堰, 出口消能采用底流型式, 设宽尾 墩, 消力池水深 $8.3 \mathrm{~m}$, 池长 $70 \mathrm{~m}$, 池宽 $46 \mathrm{~m}$ 。引水系统布置 在左岸, 采用发电引水隧洞与施工导流隧洞结合的方式, 设置放水塔作为发电引水系统进水口, 按一洞三机方式供 水 $[6]$ 。

\section{2. 监测概况}

由于每座大坝在地质、结构、运行工况和周边环境方 面存在差异, 因此, 即便是工程等级相同的大坝, 其安全 风险也存在差异 $[7]$, 在监测设计时应考虑各种因素, 综合 设计。

大坝监测工程于 2010 年 4 月 25 日开工，至2011年6月25 日, 紧跟大坝主体工程施工, 安装完成针杆应力计4支, 基 岩变形计6套, 渗压计13支, 应变计组8套, 测缝计14支, 温度计 28 支, 倒垂装置1套, 静力水准仪 4 套, 双金属标 1 套，双金属标仪 2 套，测压管7套，钢筋计6支，消力池针杆 应力计8支, 钢筋计6支, 共计完成 134 套, 占监测仪器设备 总数的 $73.2 \%[8]$ 。

\section{3. 大坝监测成果分析}

\section{1. 环境量分析}

那比水电站碾压混凝土坝最大坝高 $68.5 \mathrm{~m}$, 坝顶高程 $358.50 \mathrm{~m}$, 坝顶全长 $246.5 \mathrm{~m}$ 。水库总库容 5720 万 $\mathrm{m}^{3}$, 正常 蓄水位 $355.00 \mathrm{~m}$, 水库设计洪水位 $355.00 \mathrm{~m}$, 校核洪水位 $356.64 \mathrm{~m}$ 。那比水电站于 2010 年 12 月 26 日起一期下闸蓄水, 下闸蓄水前水位为 $302.50 \mathrm{~m}, 2011$ 年 3 月 21 日进行二期蓄 水, 封堵过水洞前水位为 $327.9 \mathrm{~m}$, 上下游水位历时过程 线见图1。

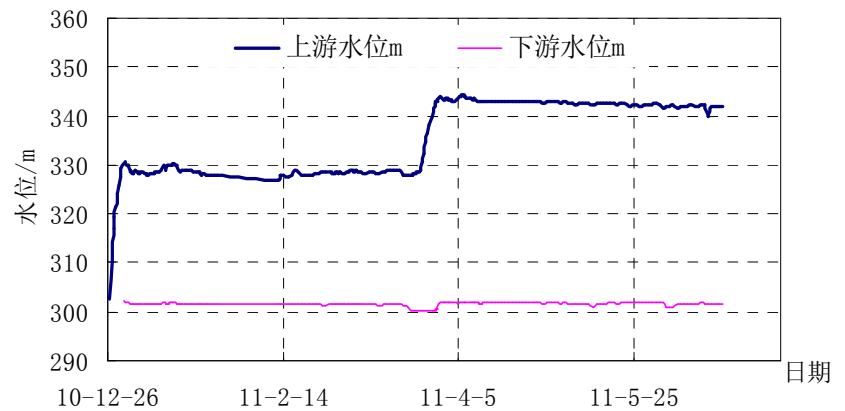

图1 上下游水位历时过程线。

一期蓄水初期库水位迅速上升, 至 2010 年 12 月 30 日大 坝上游水位涨至 $330.50 \mathrm{~m}$, 超过临时溢流过水洞底部高程 $326.80 \mathrm{~m}$, 此后几天受泄水影响, 水位有所下降。自2011 年1月至2011年3月, 库水位在 $327.00 \mathrm{~m} \sim 330.30 \mathrm{~m}$ 高程范围 内平稳波动; 下游水位在首次蓄水期内基本稳定, 在 301. 40m 302. 20m范围内平稳波动; 2011年3月21日，二 期下闸后库水位受上游来水影响, 较快地从 $327.9 \mathrm{~m}$ 上升至 最高 $343.9 \mathrm{~m}$, 溢流面过水后, 上游水位有所回落, 后长期 稳定在 $341.50 \mathrm{~m} \sim 343.00 \mathrm{~m}$ 范围内。

\section{2. 基岩变形}

用于监测坝基变形的基岩变位计分别埋设在 $4 \# 、 5 \# 、$ $6 \#$ 坝段。坝基变形主要受到大坝自重、温度荷载及上游蓄 水等因素的影响; 各基岩变形计测值在大坝自重及温度荷 载作用下测值存在小幅振荡。监测结果表明: 大坝 $4 \# 、 5 \# 、$ 6 \#坝段基岩变形均呈受压变形状态。随着大坝混凝土的浇 筑高度增加, 基岩变形逐渐增大, 上游侧基岩变形量最大 达到 $5.22 \mathrm{~mm}$ 。从整体数据上来看, 大坝坝基处于等速变形 状态, 变形速率较小。截止第三台机组发电前, 大坝基岩 变形稳定, 未出现突变值。典型基岩变形过程如图2所示。

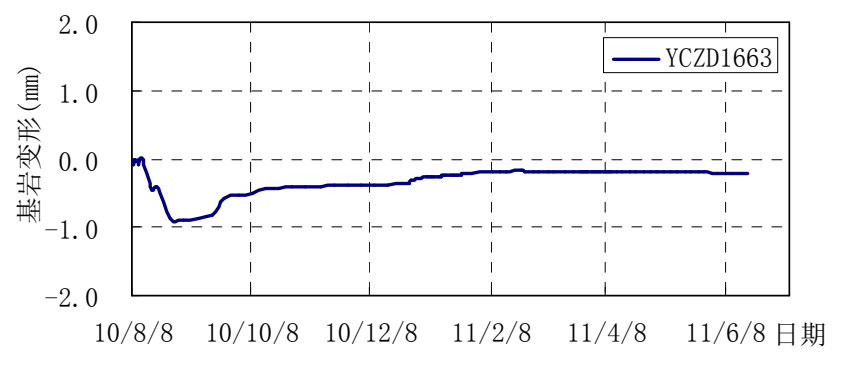

图2 基岩变形时程曲线。

\section{3. 渗透压力}

大坝坝基处共安装了6支渗压计，从各支渗压计实测 成果表明: 施工期由于上游围堰渗透性较小, 大坝浇筑过 程中, 坝前的积水较小, 坝后消力池正在施工, 处于无水 状态。因此, 坝体上下游测水位变化均较小。施工期内坝 基渗压计测值普遍较小。自2010年12月26日开始一期下闸 蓄水以来, 各支渗压计测值均存在不同幅度的增大, 部分 安装位置靠近上游面的渗压计实测渗压有所增加, 说明安 装位置的基岩渗透性较大, 渗透压力大小与上游水位变化 直接相关, 大坝蓄水后各测点渗透压力主要受大坝上游蓄 
水水位的影响; 二期下闸蓄水水位上升期间，除个别渗压 计增大外, 其余渗压计测值基本无变化。典型渗透压力过 程如图3所示。

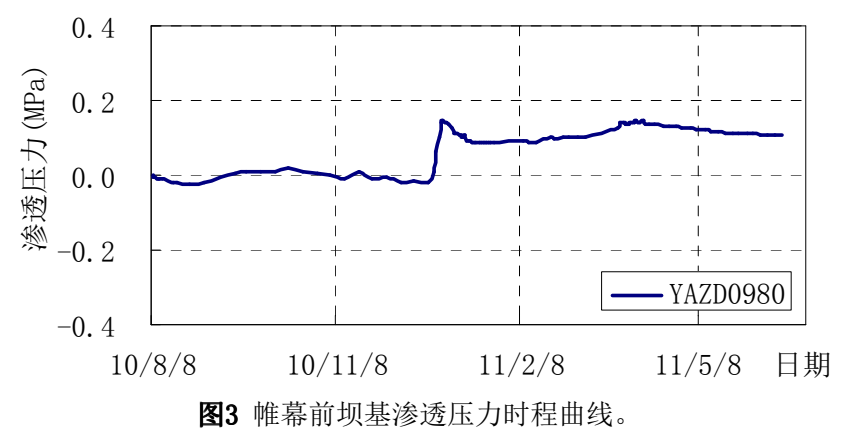

\section{4. 扬压力水位}

帷幕灌浆廊道3\# 9\#坝段, 每个坝段埋设一套测压管, 每个测压管内放置一支渗压计, 施工期内, 可以通过便携 式水位计测得孔内水位。扬压力大小与上游水位变化直接 相关，一期下闸蓄水后，孔内扬压力水位有明显的上升， 随着帷幕线下游排水孔的施工, 各测压管内扬压力水位逐 渐下降, 说明排水孔有效降低了帷幕线下游的扬压力。二 期下闸后, 随着上游水位的升高, 各测压管内扬压力水位 均有所升高, 但增加的幅度较小。典型扬压力水位过程线 如图4所示。

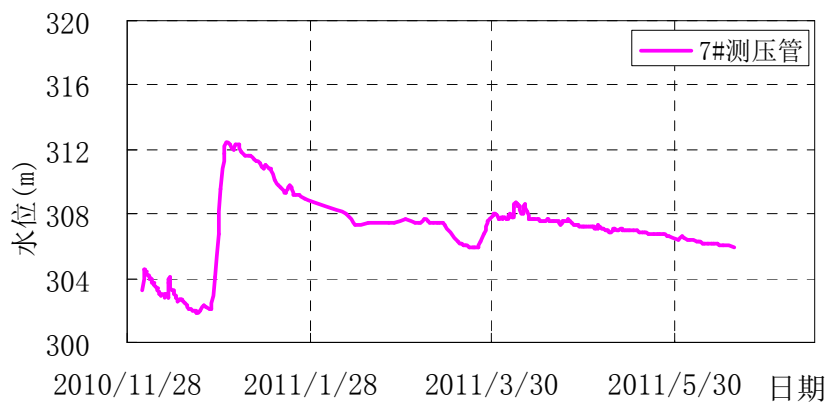

图4 扬压力水位过程线。

一期下闸蓄水期间, 扬压力大小与上游水位变化直接 相关, 孔内扬压力水位有明显的上升, 上升的幅度为 $10.35 \mathrm{~m} \sim 18.69 \mathrm{~m}$, 扬压力水位最高为 7 \#坝段, 最高时为 $321.62 \mathrm{~m}$, 接近设计警戒值, 究其原因为帷幕下游排水孔 未形成, 随着帷幕线下游排水孔的施工, 各测压管内扬压 力水位逐渐下降, 排水孔有效降低了帷幕线下游的扬压力。 二期下闸后，随着上游水位的升高各测压管内扬压力水位 升高的幅度较小，为 $1.98 \mathrm{~m} \sim 3.53 \mathrm{~m}$ 。二期下闸后，各测压 管的扬压力水位均小于设计警戒值, 测值较为稳定, 周变 幅不超过 $0.12 \mathrm{~m}$ 。

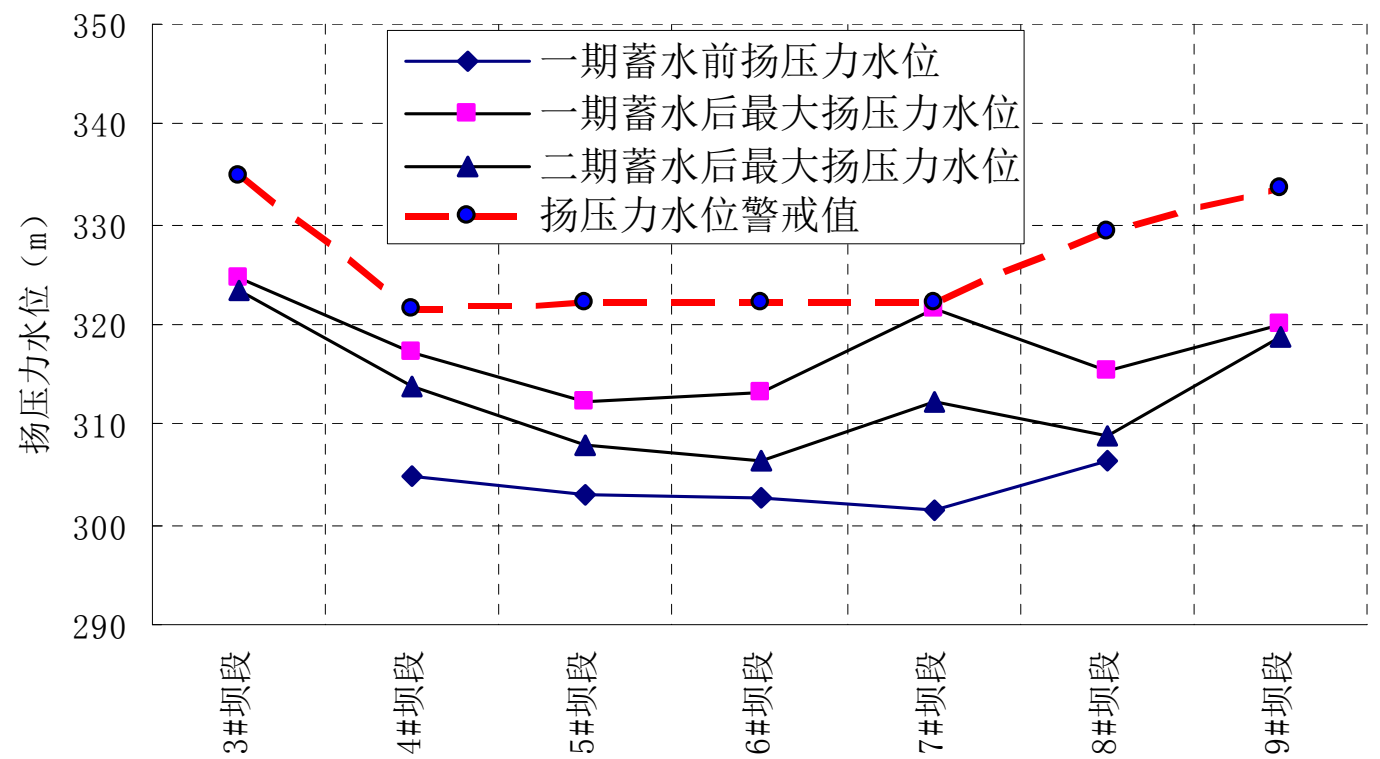

图5 扬压力水位过程线。

\section{5. 坝块接缝开合度}

从各测缝计实测成果看, 各测点变化规律基本一致。 随着温度的升高, 5\#-6\#坝段接缝开度逐渐回落, 已趋于 稳定, 其余坝段接触部位接缝开度较小。下闸蓄水后绝大 部分测缝计测值已逐渐减小并趋于稳定, 坝缝有逐步闭合 的趋势, 最大变化速率为 $0.004 \mathrm{~mm} / \mathrm{d}$ 。目前, 目前各坝段 接缝测值稳定, 变化速率逐渐变小。典型测缝计过程线如 图6所示。

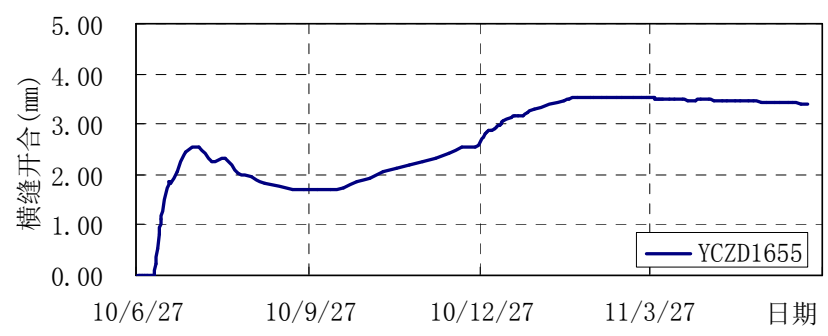

图6 测缝计位移时程曲线。 


\section{6 . 坝体温度}

用于监测坝体温度的温度计分别埋设在 $5 \#$ \#坝段和 $6 \#$ 坝段, 温度计埋设时始测温度、埋设后最高温度、以及升至温 度峰值经历时间记录如表1所示。

表1 温度计监测资料特征值。

\begin{tabular}{|c|c|c|c|c|c|}
\hline 部位 & 测点 & 始测温度 $\left({ }^{\circ} \mathrm{C}\right)$ & 最高温度 $\left({ }^{\circ} \mathrm{C}\right)$ & 升温过程经历时间（d） & 备注 \\
\hline \multirow{14}{*}{ 5\#坝段 } & YDZD4266 & 33.3 & 40.5 & 3 & 0+095断面, 294高程上游侧 \\
\hline & YDZD4255 & 33.2 & 42.9 & 3 & 0+095断面, 295高程下游侧 \\
\hline & YDZD4257 & 32.9 & 41.4 & 3 & 0+095断面, 294高程中部 \\
\hline & YDZD4259 & 24.0 & 40.3 & 3 & 0+095断面, 302高程上游侧 \\
\hline & YDZD4267 & 26.3 & 40.8 & 4 & 0+095断面, 311高程上游侧 \\
\hline & YDZD4273 & 28.5 & 33.3 & 3 & 0+095断面, 311高程中部 \\
\hline & YDZD4254 & 28.5 & 38.9 & 3 & 0+095断面, 311高程下游侧 \\
\hline & YDZD4275 & 23.4 & 35.4 & 41 & 0+101断面, 330.75高程上游侧 \\
\hline & YDZD4272 & 19. 8 & 34.9 & 42 & 0+101断面, 331.5高程上游侧 \\
\hline & YDZD4274 & 22.9 & 34.5 & 42 & 0+101断面, 332. 25高程上游侧 \\
\hline & YDZD4276 & 19.6 & 28.4 & 32 & 0+101断面, 340高程中部 \\
\hline & YDZD4279 & 14.5 & 28.7 & 9 & 0+101断面, 341高程中部 \\
\hline & YDZD4277 & 14.8 & 26.7 & 27 & 0+101断面, 343高程中部 \\
\hline & YDZD4278 & 15.5 & 26.3 & 39 & 0+101断面, 344高程中部 \\
\hline \multirow{9}{*}{ 6\#坝段 } & YDZD4261 & 34.1 & 40.8 & 4 & 0+125断面, 294高程上游侧 \\
\hline & YDZD4258 & 28.7 & 46.2 & 3 & 0+125断面, 294高程下游侧 \\
\hline & YDZD4253 & 27. 4 & 41.0 & 4 & 0+125断面, 294高程中部 \\
\hline & YDZD4269 & 27.9 & 37.2 & 2 & 0+125断面, 302高程上游侧 \\
\hline & YDZD4270 & 26.1 & 40.3 & 3 & 0+125断面, 311高程上游侧 \\
\hline & YDZD4265 & 29. 0 & 39.2 & 3 & 0+125断面, 311高程中部 \\
\hline & YDZD4256 & 30.3 & 34.6 & 3 & 0+135断面, 311高程中部 \\
\hline & YDZD4268 & 30.1 & 39.6 & 3 & 0+125断面, 311高程下游侧 \\
\hline & YDZD4263 & 32.7 & 74.6 & 3 & 0+117断面, 310.5高程溢流面 \\
\hline
\end{tabular}

监测结果表明:

(1)碾压混凝土施工过程中，由于正值暑期，碾压混凝 土入仓温度较高加之混凝土的水化热较高, 导致浇筑混凝 土的最高温度均较高。

(2)碾压混凝土入仓后，3天时间内混凝土水化热达到 最高温度。

(3)施工过程中, 通水冷却加速了碾压混凝土的水化热 消散。5号、6 号坝段监测温度达到最高水化热温度后回落。

(4) 5 号坝段上游侧, 311高程以上碾压混凝土浇筑, 热 量向下部传递, 导致311高程碾压混凝土温度抬升。6 号坝 段由于下游侧溢流面施工, 溢流面高强混凝土的水化热很 大, 且溢流面混凝土没有通水冷却措施, 致使热量不断向 先浇筑的碾压混凝土内部传递, 导致先期浇筑的碾压混凝 土温度的抬升 $[9]$ 。

对部分混凝土最高温度较大的部位进行现场排查, 未 发现温度裂缝的产生。

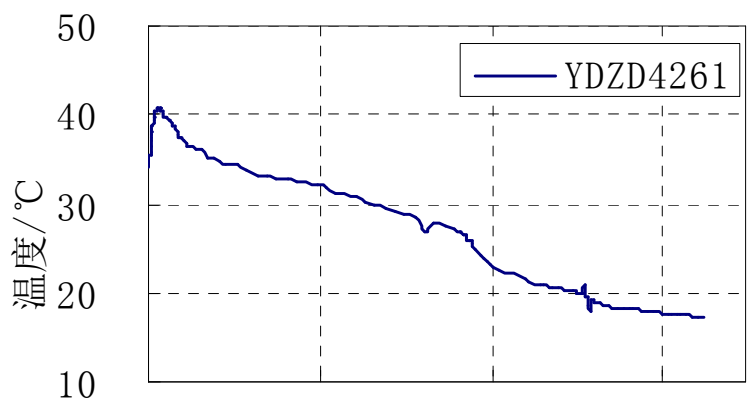

$10 / 5 / 2110 / 9 / 2111 / 1 / 21 \quad 11 / 5 / 21$ 时间 图7 温度计变化时程曲线。

大坝 326 高程及以上各支温度计变化规律变化较为一 致: 大坝混凝土浇筑初期, 在混凝土水化热消散的影响下, 各支温度计测值均存在明显升高, 之后各温度计测值变化 
因其埋设位置的不同而有所不同, 部分温度计温度下降的 过程中受后浇混凝土水化热传递影响而有所回升。根据温 度计实测监测成果可知, 326 高程及以上坝块的各支温度 计最大测值均处于设计允许范围内, 大坝温度场安全性态 正常。

\section{4. 消力池监测成果分析}

\section{1. 针杆应力计}

针杆最大压应力为 $22.80 \mathrm{MPa}$, 距坝轴距 $106.55 \mathrm{~m}$, 最 大拉应力为 $32.90 \mathrm{MPa}$, 距坝轴距 $76.55 \mathrm{~m}$, 最小拉应力为 4. $77 \mathrm{MPa}$, 最小压应力为 $18.78 \mathrm{MPa}$, 消力池底板针杆应力 均处于正常范围内; 消力池底板左板块加固结构针杆应力 均增加, 针杆安装埋设初期, 由于针杆上部混凝土浇筑, 针筋桩呈受压状态, 针杆应力呈负值增加。应力增加速率 较大, 均超过 $1 \mathrm{Mpa} / \mathrm{d}$ 。随着浇筑的完成, 针杆应力计测值 逐渐减小, 针杆应力变化趋于平缓, 下闸蓄水期内, 针杆 应力计受大坝泄水影响产生的变幅不大, 加固结构有效地 阻止了消力池底部岩体的卸荷回弹。

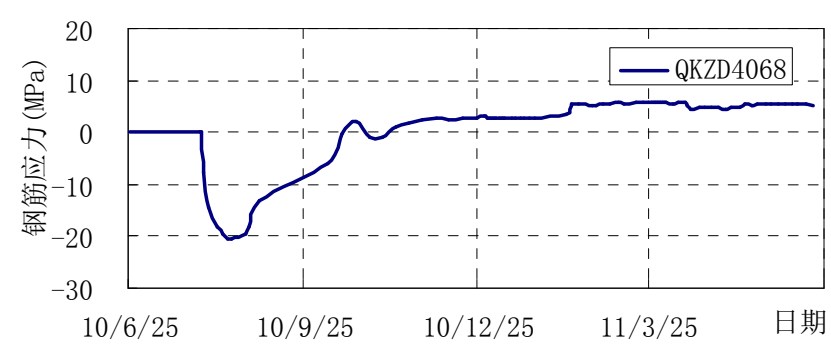

图8 针杆应力计变化时程线。

\section{2. 钢筋计}

钢筋计最大压应力为 $41.97 \mathrm{MPa}$, 最小压应力为 9. $72 \mathrm{MPa}$, 最大拉应力为 $23.13 \mathrm{MPa}$, 最小拉应力为 $16.42 \mathrm{MPa}$, 消力池底板针杆应力总体正常; 消力池消力池底板左板块 钢筋应力均增加, 安装埋设初期, 由于面层混凝土浇筑, 钢筋呈受拉状态, 钢筋应力呈正值增加。应力增加速率较 大, 均超过 $1 \mathrm{Mpa} / \mathrm{d}$ 。

温度是导致钢筋应力变化的一个重要因素, 钢筋应力 与温度呈负相关性, 即温度上升, 压应力增大, 温度降低, 拉应力增大 $[10]$ 。随着温度的上升, 部分钢筋计受到温度 应力的影响, 压应力有所增长。

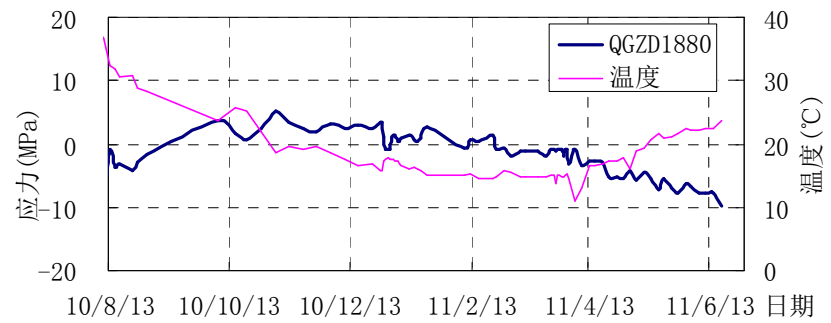

图9 钢筋计时程曲线。

\section{5. 结论}

（1）变形及位移：大坝基岩变形计在埋设前期易受大 坝自重、温度荷载等影响, 存在小幅波动, 随着坝体的增 高, 基岩变形值逐渐增加; 大坝接缝总体正常, 个别测缝 测值较大需继续加强观测; 各坝段差异沉降及坝基水平位 移均处于较小变化范围。

（2）渗透压力及扬压力: 帷幕前后渗透压力的大小表 明帷幕灌浆的效果较好; 下闸蓄水后, 扬压力变化随水位 的升降呈规律性变化。

（3）应力应变: 消力池底板针筋桩针杆应力及面层钢 筋计受下闸蓄水影响不大, 其变化跟混凝土浇筑有关, 另 外受温度应力的影响也较大, 钢筋应力与温度呈负相关性。

（4）坝体温度: 通过采用通水冷却可以有效地加速碾 压混凝土的水化热消散, 温控效果较好, 温度达到最大值 后逐渐回落。经现场排查, 未发现温度裂缝。观测后期大 坝内部温度主要受库水及环境温度影响, 大坝温度场安全 性态正常。

\section{参考文献}

[1] 何金平, 张博, 施玉群. 水电自动化与大坝监测大坝安全监 测中的几个基本概念问题 [J]. 水电自动化与大坝监 测, 2009, 6, 33 (3) : 51-54

[2] 赵志仁, 赵永, 程君敏. 大坝安全监测设计与施工技术的分 析研究 [J]. 大坝观测与土工测试, 2001, 2, 25 (1) : 28-32

[3] 季凡, 武方洁, 肖桃仙. 缅甸道耶坎面板堆石坝蓄水期安全 状况分析 [J]. 人民长江, 2015, 12, 46 (24) :94-96

[4] 王玉洁, 周建波, 董永. 水电站大坝安全监测资料分析现状 及展望 $[J]$. 大坝与安全, 2015, 5, 50-57

[5] 尚层. 新疆平原水库大坝安全监测成果实例分析 [J]. 水资 源与水工程学报, 2015, 10, 26(5) :219-223

[6] 广西百色水利电力设计院. 广西田林县那比水电站工程初 步设计文件 [R]. 2009

［7］杨帅东. 广西田林县那比水电站工程三期下闸蓄水工程安 全监测报告 $[R]$. 广州, 珠江水利委员会珠江水利科学研究 院那比水电站安全监测工程项目部. 2011.8

８］江伟国, 苏玉莲, 徐芗. 大坝安全监测项目设置和测点布置 研究 $[J]$. 水利水文自动化, 2008, 9, 3:7-13

[9] 熊成林, 武学毅, 任家正, 李贺新. 呼和浩特抽水蓄能电站安 全监测布设及施工期监测成果分析 $[\mathrm{J}]$. 中国三 峡, $2013,12,15$ (6) : 94-100

[10] 李晓辉. 张峰水库大坝初蓄期监测资料分析 $[\mathrm{J}]$. 水电自动 化与大坝监测, $2010,10,34$ (5) :68-73 